Jurnal Keperawatan Padjadjaran

ISSN 2338-5324 (print)

ISSN 2442-7276 (online)

Online di http://jkp.fkep.unpad.ac.id

DOI : $10.24198 / \mathrm{jkp}$

\title{
Food and Activities Taboos among Sundanese Pregnant Women
}

\author{
Mira Trisyani Koeryaman ${ }^{1}$, Kim Hee Kyung ${ }^{2}$, Restuning Widiasih ${ }^{3}$ \\ ${ }^{1,3}$ Faculty of Nursing Universitas Padjadjaran, Bandung, Indonesia \\ ${ }^{2}$ Department of Nursing Kongju National University, Gongju, South Korea \\ Corresponding Email: mira.trisyani@unpad.ac.id
}

Submitted: 24-08-2018 Accepted: 15-04-2019 Published: 28-04-2019

\begin{abstract}
Taboos are found everywhere including Indonesia. There are different types of taboos in Indonesia especially during pregnancy. This study aimed to identify the practice of taboos related to food and activities among Sundanese pregnant women in West Java, a province with the largest population. A cross-sectional study was conducted with 312 pregnant women, who come to antenatal care at maternal and child health clinics of hospital, health care center and private midwifery clinics at four districts area in West Java province (Cianjur, Bandung, Sumedang and Garut) from October-December 2014. The data were selected purposively used the questionnaires included important demographic characteristics and questions regarding food and activities taboos during pregnancy. SPSS Win.12.0 were used for data analysis. The practice of food and activities taboo among pregnant women showed were about $29.4 \%$ very often, $42.1 \%$ often, $22.4 \%$ rarely, and $6.1 \%$ never in avoid to eat certain foods and to do particular activities during pregnancy. No statistically significant association was found between food and activities taboo during pregnancy and data demographics of respondents $(p>.05)$. Still often done by pregnant women in avoid to eat certain foods and restriction to do particular activities. To assess the true picture we need to conduct larger studies in the community with interview method. These findings would be an important information for nurses in developing health education in maternal periods, and considering women's culture and beliefs in nursing care plan.
\end{abstract}

Keywords: Activities, foods, taboos, pregnant women. 
Mira Trisyani: Food and Activities taboas among Sundanese Pregnant Women in West Java

\section{Introduction}

The traditional background sometimes influences of the woman's behavior during pregnancy. Maintaining a healthy pregnancy is very important to the general health of the pregnant mother and her fetus. According to World health organization (2016), Indonesia is one of the country has the biggest maternal mortality ratio (MMR) in South East Asia and the larger number of mortality contribution. The most frequently of the causes of maternal (pregnancy-related) deaths still dominate by haemorrhage $30.3 \%$, hypertension $27.1 \%$, and $7.3 \%$ infection (Soedarmono, 2017). There are several factors that explain why maternal mortality is still high, it can be attributed to antenatal care, nutritional status of pregnant women, success rates of maternal and infant health services, family planning programs, environmental conditions, and socio-economic conditions (WHO, 2016).

The ignorance about nutritional needs and do any activities during pregnancy worsens the outcomes of pregnancy. Commonly, maternal mortality are often rationalized through assumption that mother may have done wrong during pregnancy such as unattended prenatal care or belief in certain activity (eg, taboos).

In order to get wellness throughout the pregnancy and into early parenthood, pregnant woman and her family should have a proper planning and preparation for the pregnancy. Unfortunately, in Indonesia, it's a common phenomenon that pregnancies happen expectantly. Many married women did not want to be pregnant after having two or three children, but they were not using contraceptives, or they were using methods with relatively high failure rates.

In exploring the food and activities taboos during pregnancy, for example Ali (2004) found that pregnant mothers believing if their restricting all foods during the first 6 months that would be easy to labor a small baby. Similarly, there is considerable evidence of women's beliefs and practices regarding food restriction during pregnancy and lactation in Korea, that women self-food restriction as Asian women are advised to avoid cold foods because they are not good for the mother and baby. Thus, this self-restriction eating certain food differs from because food unavailable or poverty. However, the cultural tradition also effects as a cause of dietary behavior. Even though, without a scientific basis, popular myths about the mother's diet during pregnancy and breastfeeding can become barriers to maternal health and lead to unnecessary dietary restrictions in pregnancy (Goun, 2017).

Pregnancy and childbirth have universally been accepted as a natural means of continuing human's life, although in Indonesia, the cultural variation in beliefs about pregnancy and childbirth are considered more important and also the specific social aspects by many ethnic groups. Therefore, many beliefs and practices relating to childbearing process must be observed by the woman and her family to ensure the health and well-being of herself and her newborn baby (Liamputtong Rice, 2000).

Considering the importance of daily activities including meeting nutritional needs and carrying out appropriate activities during pregnancy and the direct impact of pregnancy outcomes, this study will identify pregnant women who practice food and activities according to general characteristics.

\section{Method}

A cross-sectional study was conducted with 300 pregnant women who attended to antenatal care at maternal and child health clinics of hospital, health care center (Puskesmas) and private midwifery clinics at four districts area in West Java province (Cianjur, Bandung, Sumedang and Garut) from October-December 2014. A minimum sample of 300 pregnant women was required using 5 percent level of significance, a bound error of $5 \%$ and an anticipated prevalence of 50 percent. The researcher had discuss with the head of maternal and child health clinic, and division of education hospital to explain the purpose of study, procedure and conduction of the data collection and how to respond any questions. This study was conducted in accordance and approval of the nursing faculty of Universitas Padjadjaran. The permission obtained from the directors of those hospitals and facilitate to processing 
Mira Trisyani: Food and Activities taboas among Sundanese Pregnant Women in West Java

data collection. A cover letter form give to the participants explained about the purpose of the study and instructions how to complete the questionnaire. The form asks for decision to participants if they would to participate in this research or not. In addition, this cover letter specified that the participant is completely voluntary with no risk or benefits. Confidentially were maintained by the list of names or any identifying personal information on questionnaires. These questionnaires kept for five years

The questionnaires included important demographic characteristics and questionnaires related with food and activities taboos during pregnancy. Hypothesize measurement models based on the questionnaires were tested through confirmatory factor analysis (number of cases $=30$ ). Using correlation technique score items with total score through coefficient correlation product-moment was computed and alpha Cronbach's. Internal Consistency Reliability was estimated using Cronbach's coefficient alpha. The validity and reliability coefficients for the subscale of taboos instruments was Cronbach's $\alpha=.86$

Appropriate statistical analyses were performed with the software SPSS 1Win. 12.0 For Windows. Frequencies and percentages were calculated for demographic profile like women ages, gestational age, have been pregnant, education background, occupation, and monthly family income. Mean and standard deviation are reported for analysis result questionnaires. Statistical analysis included summation of scores of each participant $(n=300)$ and measures of variability (range, mean and standard deviation). Furthermore, this study are for expanded of statistical analysis and it used by t-tests. The level of statistical significant was set on .05 to see if there was a significant finding between practical of food and activities taboos across to demographic data.

\section{Result}

Table 1 Distribution Frequency of Demography Characteristics of the Pregnant Women

\begin{tabular}{|c|c|c|c|}
\hline Characteristic & Category & $\mathbf{F}$ & $\%$ \\
\hline \multirow[t]{4}{*}{ Age } & Less than 20 & 30 & 10 \\
\hline & $20-29$ & 169 & 56 \\
\hline & $30-39$ & 77 & 26 \\
\hline & 40 or greater & 24 & 8 \\
\hline \multirow[t]{3}{*}{ Gestational Age } & Trimester I & 59 & 20 \\
\hline & Trimester II & 102 & 34 \\
\hline & Trimester III & 139 & 46 \\
\hline \multirow[t]{3}{*}{ Parity } & Primi gravida & 128 & 43 \\
\hline & Multigravida & 142 & 47 \\
\hline & Grande multigravida & 30 & 10 \\
\hline \multirow[t]{3}{*}{ Education } & Low education & 242 & 81 \\
\hline & Middle education & 31 & 10 \\
\hline & Higher education & 27 & 9 \\
\hline \multirow[t]{2}{*}{ Employment Status } & Employed & 79 & 26 \\
\hline & Not employed & 221 & 74 \\
\hline \multirow[t]{3}{*}{ Monthly Family Income } & Less than IDR $1,000,000$ & 141 & 47 \\
\hline & IDR $1,000,000$ to IDR $2,000,000$ & 101 & 34 \\
\hline & IDR $2,000,000$ or more & 58 & 19 \\
\hline
\end{tabular}


Mira Trisyani: Food and Activities taboas among Sundanese Pregnant Women in West Java

Table 2 Percentage Distribution of Various Food and Activities Taboos during Pregnancy by Frequency Level

\begin{tabular}{|c|c|c|c|c|c|}
\hline Question Items & $\begin{array}{c}\text { Very Often } \\
\text { n }(\%)\end{array}$ & $\begin{array}{l}\text { Often } \\
\text { n (\%) }\end{array}$ & $\begin{array}{l}\text { Rarely } \\
\text { n }(\%)\end{array}$ & $\begin{array}{l}\text { Never } \\
\text { n }(\%)\end{array}$ & $\mathbf{M} \pm \mathbf{S D}$ \\
\hline Avoid too much sleeping & $8(12.7)$ & $127(42.3)$ & $115(38.3)$ & $20(6.7)$ & $2.61 \pm .79$ \\
\hline Avoid eating a fatty food & $64(21.3)$ & $131(47.3)$ & $93(31.0)$ & $12(4.0)$ & $2.82 \pm .81$ \\
\hline $\begin{array}{l}\text { Avoid eating seafood like eel, shrimp, } \\
\text { octopus, crab, squid, ray fish, other } \\
\text { fish }\end{array}$ & $10(3.3)$ & $111(37.0)$ & $125(42)$ & $54(18.0)$ & $2.26 \pm .79$ \\
\hline Husband avoid to kill the animal & $85(28.3)$ & $144(48.0)$ & $68(22.7)$ & $3(1.0)$ & $3.04 \pm .74$ \\
\hline $\begin{array}{l}\text { Avoid to see the wild and frighten } \\
\text { animal }\end{array}$ & $45(15.0)$ & $134(44.7)$ & $85(28.3)$ & $36(12.0)$ & $2.63 \pm .88$ \\
\hline Avoid to hate someone & $197(65.7)$ & $79(26.3)$ & $16(5.3)$ & $8(2.7)$ & $3.55 \pm .72$ \\
\hline Avoid to rude behave to others & $208(69.3)$ & $71(23.7)$ & $13(4.3)$ & $8(2.7)$ & $3.60 \pm .70$ \\
\hline Avoid to going out in the evening & $97(32.3)$ & $161(53.7)$ & $32(10.7)$ & $10(3.3)$ & $3.15 \pm .74$ \\
\hline $\begin{array}{l}\text { Avoid to watching criminal's } \\
\text { television program }\end{array}$ & $58(19.3)$ & $174(58.0)$ & $64(21.3)$ & $4(1.3)$ & $2.95 \pm .68$ \\
\hline Avoid to hearing the bad news & $88(29.3)$ & $185(62.0)$ & $27(9.0)$ & 0 & $3.20 \pm .59$ \\
\hline $\begin{array}{l}\text { Restriction to eat some kind of fruits } \\
\text { and vegetable like pineapple, avocado, } \\
\text { pomegranate, guava, orange squash, } \\
\text { durian, jack-fruit, papayas, sugar cane, } \\
\text { and eggplant }\end{array}$ & $55(18.3)$ & $55(18.3)$ & $113(37.7)$ & $77(25.7)$ & $2.29 \pm .04$ \\
\hline Avoid to see a moon eclipse & $251(83.7)$ & $48(16.0)$ & $1(0.3)$ & 0 & $3.83 \pm .38$ \\
\hline Avoid to drink a cold water & $61(20.3)$ & $145(48.3)$ & $78(26.0)$ & $16(5.3)$ & $2.84 \pm .81$ \\
\hline $\begin{array}{l}\text { Avoid to eat in big plate during } \\
\text { pregnancy }\end{array}$ & $61(20.3)$ & $145(48.3)$ & $78(26.0)$ & $16(5.3)$ & $2.84 \pm .81$ \\
\hline Avoid to cut hair & $61(20.3)$ & $145(48.3)$ & $78(26.0)$ & $16(5.3)$ & $2.84 \pm .81$ \\
\hline Avoid to fishing & $61(20.3)$ & $145(48.3)$ & $78(26.0)$ & $16(5.3)$ & $2.84 \pm .81$ \\
\hline $\begin{array}{l}\text { Avoid to preparing the baby's needs } \\
\text { during pregnant }\end{array}$ & $61(20.3)$ & $145(48.3)$ & $78(26.0)$ & $16(5.3)$ & $2.84 \pm .81$ \\
\hline Total & $88(29.4)$ & $126(42.1)$ & $67(22.4)$ & $18(6.1)$ & $2.95 \pm .33$ \\
\hline
\end{tabular}

Table 3 The Correlation between Demographic Characteristics Data and Taboos

\begin{tabular}{|c|c|c|c|c|c|c|}
\hline \multirow{2}{*}{$\begin{array}{c}\text { Demographic } \\
\text { Data }\end{array}$} & \multicolumn{2}{|c|}{ Food taboos } & \multicolumn{2}{|c|}{ Activities taboos } & \multicolumn{2}{|c|}{ Total Score } \\
\hline & Mean \pm SD & $\begin{array}{c}\text { F or } t \\
\text { (p) }\end{array}$ & Mean \pm SD & $\begin{array}{c}\text { F or } t \\
\text { (p) }\end{array}$ & Mean \pm SD & $\begin{array}{c}\text { F or } t \\
\text { (p) }\end{array}$ \\
\hline \multicolumn{7}{|l|}{ Age } \\
\hline$<20$ & $2.90 \pm .41$ & $5.15(.12)$ & $2.58 \pm .35$ & $2.67(.05)$ & $2.91 \pm .41$ & $.16(.93)$ \\
\hline $20-29$ & $3.20 \pm .50$ & & $2.77 \pm .40$ & & $2.96 \pm .32$ & \\
\hline $30-39$ & $3.06 \pm .49$ & & $2.69 \pm .39$ & & $2.94 \pm .33$ & \\
\hline$>40$ & $3.33 \pm .48$ & & $2.82 \pm .41$ & & $2.95 \pm .34$ & \\
\hline \multicolumn{7}{|l|}{ Gestational Age } \\
\hline Trimester I & $3.29 \pm .46$ & $3.00(.06)$ & $2.85 \pm .41$ & $3.41(.06)$ & $2.96 \pm .37$ & $.18(.83)$ \\
\hline Trimester II & $3.13 \pm .53$ & & $2.67 \pm .40$ & & $2.96 \pm .30$ & \\
\hline Trimester III & $3.10 \pm .48$ & & $.72 \pm .39$ & & $2.94 \pm .33$ & \\
\hline
\end{tabular}

$$
\text { Parity }
$$


Mira Trisyani: Food and Activities taboas among Sundanese Pregnant Women in West Java

\begin{tabular}{|c|c|c|c|c|c|c|}
\hline Primigravida & $3.15 \pm .49$ & 03(.97) & $2.71 \pm .42$ & $.26(.77)$ & $2.95 \pm .36$ & $.49(.61)$ \\
\hline Multigravida & $3.14 \pm .51$ & & $2.74 \pm .38$ & & $2.94 \pm .29$ & \\
\hline $\begin{array}{l}\text { Grande } \\
\text { multigravida }\end{array}$ & $3.16 \pm .48$ & & $2.76 \pm .41$ & & $3.00 \pm .35$ & \\
\hline \multicolumn{7}{|l|}{$\begin{array}{l}\text { Education } \\
\text { background }\end{array}$} \\
\hline Low education & $3.19 \pm .49$ & $1.45(.23)$ & $2.77 \pm .42$ & $1.83(.12)$ & $2.94 \pm .34$ & $1.75(.14)$ \\
\hline $\begin{array}{l}\text { Middle } \\
\text { education }\end{array}$ & $3.03 \pm .51$ & & $2.60 \pm .38$ & & $2.86 \pm .31$ & \\
\hline $\begin{array}{l}\text { Higher } \\
\text { education }\end{array}$ & $3.05 \pm .48$ & & $2.70 \pm .41$ & & $3.08 \pm .27$ & \\
\hline \multicolumn{7}{|l|}{$\begin{array}{l}\text { Employment } \\
\text { status }\end{array}$} \\
\hline Employment & $3.13 \pm .49$ & $.35(.55)$ & $2.73 \pm .38$ & $2.76(.39)$ & $2.95 \pm .32$ & $0.34(.56)$ \\
\hline $\begin{array}{l}\text { Not } \\
\text { employment }\end{array}$ & $.16 \pm .50$ & & $2.73 \pm .41$ & & $2.95 \pm .33$ & \\
\hline \multicolumn{7}{|l|}{$\begin{array}{l}\text { Monthly family } \\
\text { income }\end{array}$} \\
\hline $\begin{array}{l}<\mathrm{IDR} \\
1,000,000\end{array}$ & $3.22 \pm .48$ & $2.97(.05)$ & $2.79 \pm .41$ & $3.02(.05)$ & $2.93 \pm .35$ & $.35(.71)$ \\
\hline $\begin{array}{l}\text { IDR } 1,000,000- \\
2,000,000\end{array}$ & $3.12 \pm .52$ & & $2.71 \pm .40$ & & $2.96 \pm .32$ & \\
\hline $\begin{array}{l}>\text { IDR } \\
2,000,000\end{array}$ & $3.03 \pm .49$ & & $2.64 \pm .37$ & & $2.97 \pm .29$ & \\
\hline
\end{tabular}

This research findings divide into demographics characteristic data, practically of food and taboos activities and correlation between demographics data with food and activities taboos. The demographic profiles of the samples are presented in Table 1. Pregnant women in all of period of pregnancies whose came to obstetric clinic without high-risk condition. All the participants dominated by maternal age 20 and 29 years $(56.3 \%)$. The gestational age in trimester III $(46 \%)$ which week's gestation was set based on the subjects self-report of their due date and the medical record. Most of women in multigravida $(43 \%)$, and $(80.7 \%)$ of participants were loweducation category, which they education level were elementary school and junior secondary school. Also the pregnant women mostly as a housewife $(73.7 \%)$ and their monthly incomes about IDR 1,000,000 (\$100 USD) or less.

The table 2 showed about practically of food and activities taboos among pregnant women during pregnancy. The higher responses from participants answered is "often" (42.1\%). Which the highest mean for question "avoid to seeing a moon eclipse" (3.83 \pm .38$)$, it is describes that some pregnant women forbidden to see moon eclipse $(83.7 \%)$. The higher mean in taboos activity was $(3.60 \pm .70)$ for a question "avoid to rude behave to others", indicating that some of pregnant women $(69.3 \%)$ keep away from unpleasant behavior during pregnancy. Other responses very often frequently by women pregnant was "avoid to hate someone" $(65.7 \%)$ with mean (3.55 \pm .72$)$. Furthermore the others higher mean score findings according to taboos activity for questions: "avoid to hear the bad news during pregnancy" (3.20 \pm .59$)$, "avoid going out in the evening" (3.15 \pm .74$)$, and question for "husband avoid to kill the animal" (3.04 \pm .74$)$, and the lowest score is the question by "avoid to eat some seafood like eel, shrimp, octopus, crab, squid, ray fish, other fish" (2.26 \pm .79$)$. Other responses from participant as food taboos was "restriction to eat some kind of fruits and vegetable like pineapple, avocado, 
Mira Trisyani: Food and Activities taboas among Sundanese Pregnant Women in West Java

pomegranate, guava, orange squash, durian, jack-fruit, papayas, sugar cane, and eggplant" (2.29 \pm .04$)$, although most participant answered in "rarely" (37.7\%).

\section{Discussion}

Our study show a high percentage of respondents' taboos in belief to avoid some activities during pregnancy. If we compare all activities of Sundanese pregnant women, they are prefer to do a good things than negative activities, such as avoid to kill the animal, avoid to rude behave to others, and avoid to hearing the bad news. Although there are some activities that are avoided by pregnant women which have nothing relevance with a good or bad behave, including avoid too much sleeping, avoid to see the wild and frighten animal, avoid to going out in the evening, avoid to watching criminal's television program, avoid to see a moon eclipse, avoid to cut hair, avoid to fishing, and avoid to preparing the baby's needs during pregnant.

The reason for these high numbers could be, because the respondents were more health conscious and belief that activities during pregnancy have contribution to their pregnancy outcomes. Drawing from this result that the majority of women avoid eating certain foods such as sea foods, fruits and vegetables. The most common reason women said the reason for avoiding eating certain fruits or vegetables is fear of having an abortion. Other reasons avoiding for such activities related to the taboos' during pregnancy had about labor curse. Many mothers are told to avoid eating in a big plate because it thought to cause large placenta and labor obstruction. Similarly, there is considerable evidence of women's beliefs and practices regarding food restriction during pregnancy and lactation in Pakistan, reported that pregnant mothers believing if their restricting all foods during the first 6 months that would be easy to labour a small baby (Ali 2004). Also, the study from Schlenker (2015) identified a number of factors that are likely to influence personal perception of foods. How people perceive themselves in relation to food and food patterns plays a role in their attitudes toward food and personal eating behaviour.

This study in line with previous studies in Bangladesh showed that, most of the pregnant mother had a tendency of not to eat certain foods such as meat, they believed that it would lead to the birth of a large baby, which would hamper the smooth delivery and they have beliefs if they eat 'duck meat' might cause of asthma, cold and cough, allergy, pressure, digestion problem and afraid the baby will be voice like a duck. Also 'goat meat' might cause asthma, hot temper of child, bad smell of child's body and diabetes (Bhuiyan, 1988). Our study also showed that pregnant women avoid to eat seafood like eel, shrimp, octopus, crab, squid, ray fish, and others fish, even though they do not give any reason. However, this finding supported by study from Bhuiyan (2001) in Bangladesh and India, which they study found that women do not eat fish during pregnancy, because they beliefs eat a kind of fish could be increased movement of fetus and may cause child's Hysteria. Other reason explain by the women that "Boal fish" may cause big mouth, cold and cough disease of child. Whereas a study in India also have misbelieves about fish, their pregnant mother thinks that fish is 'hot food' and it might increase the temperature of their child. Regarding superstition about some fruits and vegetables, previous study in Bangladesh showed that, fruits like pineapple might cause miscarriage (Valenski, 2017). The study in Nigeria, also showed that most of the women believes that pineapple might cause abortion; child's skin might have eye spot like pineapple. Some women believes that black berry may cause black skin like black berry, others believe that, if they drink coconut water, their child's eyes might be white. There have also some misbelieves about tea, coffee, particularly at in local government area, in Nwangele showed that, tea, coffee might causes excessive bleeding during labor and delivery (Maduforo, 2016). Not only in Indonesia, Nigeria, and Bangladesh but also other country have the nutritional beliefs or taboos among the pregnant women. According to study in Pakistan about nutritional beliefs and practices among diabetic pregnant mothers, the finding showed that women said tea and coffee might cause child's dark skin. While, 
Mira Trisyani: Food and Activities taboas among Sundanese Pregnant Women in West Java

most of their pregnant women did not eat cauliflower, turnip and potato, as they thought that it might cause loose motion of the child. Besides, in India it was showed that their pregnant mothers did not eat milk, egg, fish, meat, onion, garlic etc. "hot food" as they think it might increase the temperature of the child (Salma, 2017).

The develops ways of eating based on ethnic or cultural background, religious beliefs, family habits, socio economic status, health status, geographic location, and personal likes and dislikes. However, the growing ethnic and cultural diversity has been acculturated individual to view food, and think about particular food is safe or unsafe to eat, good or bad will usually have a pronounced effect on that's food's acceptability to them.

Therefore, the respect of taboos is one of the things common to all humans. Taboos are found everywhere, and are always aimed at preventing some form of perceived danger or misfortune. However, various types of taboos in some countries are clear to describe the majority of pregnant women still have a big misunderstanding during pregnancy that affects their practice.

\section{Conclusion}

The findings from this study supported the practically maternal health care activity at four districts of West Java province, Indonesia have strongly influenced by taboos behavior including taboos activity and taboos food than encouraging behaviors. According to the result of this study, most of beliefs of pregnant women during pregnancy taboos activities potential give a high influence to pregnancy outcomes, particularly in restriction consume a certain foods. Our main concerning issues is that we feel these dietary restrictions leads to pregnancy complication such as anemia, malnutrition and low birth weight. Which the nutritional factors play an important role in pregnancy periods to ensure optimal birth outcomes, maternal health and determine the quality of human resources in future. Through taboos behavior, health promotion about maternal health care can accommodate with information dissemination among pregnant women.

Currently other cultural practice, pattern experiences, behaviors, opinions, beliefs, feelings, and knowledge of a community still need to be explored. Therefore, we recommend further larger studies should be conducted in the community setting in this regard to know more about the factors influence to their cultural beliefs. These studies added to nursing's knowledge based, and encourage client education. Through taboos behavior, nurse providers must provide health education for pregnant women on practically maternal health care activity.

\section{References}

Ali, N.S., Azam, S.I., Noor, R. (2004). Women's belief and Practices regarding food restrictions during pregnancy and lactation: a hospital based study. J Ayub Med Coll Abbottabad, Jul-Sep; 16(3):29-31. Retrieved from http://www.ncbi.nlm.nih.gov/pubmed.

Bhuiyan M.A.H., Chowdhury M.M.H., Malek M.A. (1988). Dietary practices and food taboos among mothers during pregnancy and after delivery in two selected rural locations of Bangladesh. Bangladesh $J$ Nutr; 1(2):105-10.

Bhuiyan A.H., Jafor N. (2001). Superstition and Malnutrition. MSc Thesis. Bangladesh: Community Nutrition Department. Institute of Nutrition and Food Science University of Dhaka.

Goun Jeong, Sung Won Park, Yeon Kyung Lee, Sun Young Ko, \& Son Moon Shin. (2017). Maternal food restrictions during breastfeeding. Korean Journal of Pediatrics, 60,70. Retrieved http://search.ebscohost. com/login.aspx?direct $=$ true $\& d b=e d b \& A N=$ $122537561 \&$ site $=$ eds-live.

Liamputtong, Pranee, Ph.D. (2005). Traditional beliefs about pregnancy and child birth among women from Chiang Mai, Northern Thailand.

Maduforo Aloysius N. (2016). Superstitions and Nutrition among pregnant women in 
Mira Trisyani: Food and Activities taboas among Sundanese Pregnant Women in West Java

Nwangele Local Government area of IMO state, Nigeria. J Res Natl Dev 20108 (2).

Soedarmono Y.S.M. (2017). The Indonesia approach to reduce maternal mortality. Congress Review. Indonesia Association of Transfusion Medicine, Jakarta, Indonesia. ISBT Science Series.

Schlenker, E.D. (2015). Nutrition and Health in Schhlenker, E.D., Gilbert, J. Williams' Essentials of Nutrition and Diet Therapy. China: Mosby, Inc. an affiliate of Elsevier Inc.

Vasilevski, V., Olah, MC. (2016). Food taboos and nutrition-related pregnancy concerns among Ethiopian women: Discursive paper. Journal of Clinical Nursing, 25, 3069-3075, doi: 10.1111/jocn.13319.

Ummy Salma Munnia, Sharmin Hossainb, Kazi Rumana Ahmedb. (2017). Nutritional beliefs and practices among diabetic pregnant mothers in a tertiary care hospital in Bangladesh. Diabetes \& Metabolic Syndrome: Clinical Research \& Reviews 11; 287-290.

WHO. (2016). WHO recommendations on antenatal care for a positive pregnancy experience. ISBN 9789241549912. 